\title{
Do bronchodilators adversely affect the prognosis of bronchial hyperresponsiveness?
}

The possible adverse effects of bronchodilators on the prognosis of bronchial hyperresponsiveness (BHR) is currently a topical subject. Studies on this subject are, however, scarce. Many studies have dealt with the immediate or short term effect of bronchodilators on BHR, but to study the effects of these drugs on the prognosis of BHR, long term well controlled studies are necessary. Such studies have started to appear in the last few years. To answer the question whether bronchodilators adversely affect the prognosis of BHR, a distinction has to be made between the effects of bronchodilators without the use of anti-inflammatory drugs and the effects of bronchodilators used in combination with anti-inflammatory drugs.

\section{Bronchodilators as monotherapy}

Since bronchodilator drugs do not have an effect on late phase asthmatic reactions, nor on the allergen provoked increase in BHR, it was generally assumed that these drugs had no long term effect on BHR. Some years ago, however, it was observed in two independent studies that inhaled terbutaline ( 2000 or $2250 \mu \mathrm{g}$ daily for $2-4$ weeks) increased BHR in some patients with asthma (less than 1.5 doubling dose of histamine). ${ }^{12}$ Two other studies in asthmatic children showed that neither terbutaline (1500 $\mu \mathrm{g}$ daily for six months), ${ }^{3}$ fenoterol (600 $\mu \mathrm{g}$ daily for four months), ${ }^{4}$ nor ipratropium bromide (120 $\mu$ g daily for four months $)^{4}$ had any effect on BHR. In a randomised single blind self controlled study the use of the $\beta_{2}$ adrenergic drug salbutamol for 12 months caused a small ( $0 \cdot 7$ doubling dose) but significant increase in BHR in 15 patients who had not used any $\beta_{2}$ adrenergic drugs during the previous year. ${ }^{5}$ The increased BHR returned to the baseline value again after inhaling ipratropium bromide for six months (fig 1). In the control group, in whom the treatment regimen was taken in the reverse order, the same trend was observed.

It is not clear what causes an increase in BHR during treatment with terbutaline ${ }^{12}$ or salbutamol. ${ }^{5}$ It may be caused by a rebound effect after stopping a $\beta_{2}$ adrenergic drug, possibly the consequence of $\beta_{2}$ adrenoceptor subsensitisation. ${ }^{12}$ In our study, however, we could not detect any subsensitisation to salbutamol in the patients during the year salbutamol was taken. ${ }^{5}$ The number and the affinity of $\beta_{2}$ adrenoceptors on circulating lymphocytes did not change, nor did the bronchodilator response to salbutamol. Although $\beta_{2}$ adrenoceptors that were functionally linked to adenylate cyclase were not specifically investigated, our observation indicates that there was probably no down regulation in the systemic burden induced by $\beta_{2}$ adrenergic drugs. Even when a down regulation of $\beta_{2}$ adrenoceptors in peripheral mononuclear blood cells is induced by treatment with $\beta_{2}$ adrenergic drugs, this does not necessarily indicate a clinically relevant subsensitisation of the airways to these drugs. It has been shown that a down regulation of $\beta_{2}$ adrenoceptors linked with a lowered metabolic adenylate cyclase activity is not associated with a change in the bronchodilator response to salbutamol. ${ }^{6}$ In our study there was no evidence of a relevant subsensitisation of $\beta_{2}$ adrenoceptor induced bronchodilatation in the airways. ${ }^{5}$

Despite these facts, subsensitisation cannot be excluded as an impaired response to a $\beta_{2}$ adrenergic drug might be more apparent as a change in the provocative concentration causing a $20 \%$ fall in $\mathrm{FEV}_{1}\left(\mathrm{PC}_{20}\right)$ than in $\mathrm{FEV}_{1}$ itself. It is possible that a $\beta_{2}$ adrenergic induced subsensitisation of $\beta_{2}$ adrenoceptors is more apparent as increased sensitivity to histamine induced bronchoconstriction through loss of a $\beta_{2}$ adrenoceptor mediated protective effect. At the present time, however, there is no evidence that a possible loss of the protective effect of a $\beta_{2}$ adrenergic agent against histamine (or any other provocative stimulus) is more sensitive in detecting an induced subsensitisation than a change in the slope of the doseresponse curve of $\mathrm{FEV}_{1}$.

Since we were particularly interested in subsensitisation to the $\beta_{2}$ adrenergic drug, we selected only those patients who had not used any $\beta_{2}$ adrenergic drugs or $\beta$ blockers during at least the year before the start of the study. ${ }^{5}$ These consisted of 15 patients who were part of a much larger group of 144 patients studied whilst taking salbutamol and ipratropium bromide for two years. The recently published data of the whole study group showed that the effect of salbutamol on BHR was similar to that of ipratropium bromide. ${ }^{7}$ The most important question in the main study was whether the effects of the continuous use of salbutamol or ipratropium bromide on decline in lung function or BHR differed from changes seen in subjects taking treatment on demand only. In asthma, BHR did not significantly increase during the two years of continuous bronchodilator treatment compared with treatment on demand. Only in patients with chronic bronchitis was there a very small decrease in $\mathrm{PC}_{20}$ after 12 months of continuous treatment in comparison with symptomatic treatment $(0.4$ doubling dose, $\mathrm{p}<0.05) .^{7}$

The recently published study of Haahtela et $a l^{8}$ showed that, with a relatively low dose of a $\beta_{2}$ adrenergic drug (terbutaline $750 \mu \mathrm{g}$ daily for two years), $\mathrm{PC}_{20}$ did not decrease but, in fact, increased by 0.5 doubling dose of histamine $(p<0.01)$ when compared with the pretreatment period. In another study a much higher dosage of the $\beta_{2}$ adrenergic drug (terbutaline $2000 \mu \mathrm{g}$ ) plus an anticholinergic drug (ipratropium bromide $160 \mu \mathrm{g}$ ) was

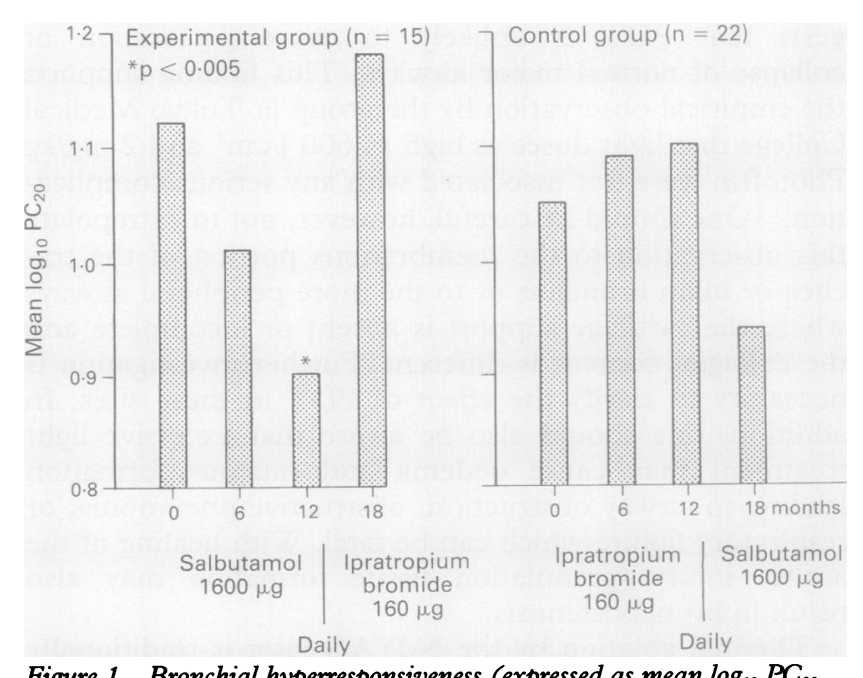

Figure 1 Bronchial hyperresponsiveness (expressed as mean $\log _{10} P C_{20}$ histamine) during 12 months treatment with salbutamol and 6 months reversed treatment regimen (control group). 
compared with the same $\beta_{2}$ adrenergic drug plus placebo for $2 \cdot 5$ years. The results showed that BHR was not increased during the continuous use of the $\beta_{2}$ adrenergic drug plus the anticholinergic drug, nor during the use of the $\beta_{2}$ adrenergic drug plus placebo. ${ }^{9}$

From all these studies we may conclude that monotherapy of bronchodilators in general does not increase BHR. In subgroups of patients and with high dosages of a $\beta_{2}$ adrenergic drug there may be an effect, but it is small (between 0.5 and 1.5 doubling dose of histamine which is virtually similar to the repeatability of the challenge test $)^{10}$ and of doubtful clinical significance, and it is very unlikely that slightly responsive patients would notice this increase in BHR. It may, however, have other consequences for patients with more severe asthma. It has been argued by Mitchell that a small increase in BHR in the whole population of asthmatic subjects results in a small increase in the number of patients with mild asthma, but in a substantial increase in the proportion of patients with moderately severe asthma (fig 2). ${ }^{11}$ According to Mitchell this drug induced change in BHR might have contributed to the increase in mortality from asthma. Indeed, an association between the prescription of fenoterol ${ }^{12}$ and (more recently) of other $\beta_{2}$ adrenergic drugs $^{13}$ and mortality from asthma was found in two epidemiological studies. It has never been proved, however, that this relationship was causal. It is more probable that overdependence on the $\beta_{2}$ adrenergic drugs delays the use of needed anti-inflammatory agents and therefore might be a cause of mortality in asthma patients. ${ }^{14}$

The effect of bronchodilators (given as monotherapy) on the decline in lung function seems of more clinical importance. We recently published the changes induced by continuous bronchodilator treatment compared with treatment on demand. ${ }^{7}$ The decline in lung function was $72 \mathrm{ml} /$ year during continuous use and $20 \mathrm{ml} /$ year during treatment on demand $(p<0.05)$. The difference in decline was observed over a two year period and needs to be confirmed in longer studies before definite conclusions can be drawn. The design of our study was single blind, and the conclusion on decline in lung function was related only to 144 of the 223 patients who completed the two year study. We do not have a reliable estimate of the decline in lung function of the remaining 79 patients, 40 of whom dropped out because of inadequate response to treatment. Of these 40 inadequately treated patients, the number of patients treated continuously was twice as high as that of those treated on demand, which might confirm the possible deleterious effects of continuous treatment. ${ }^{7}$

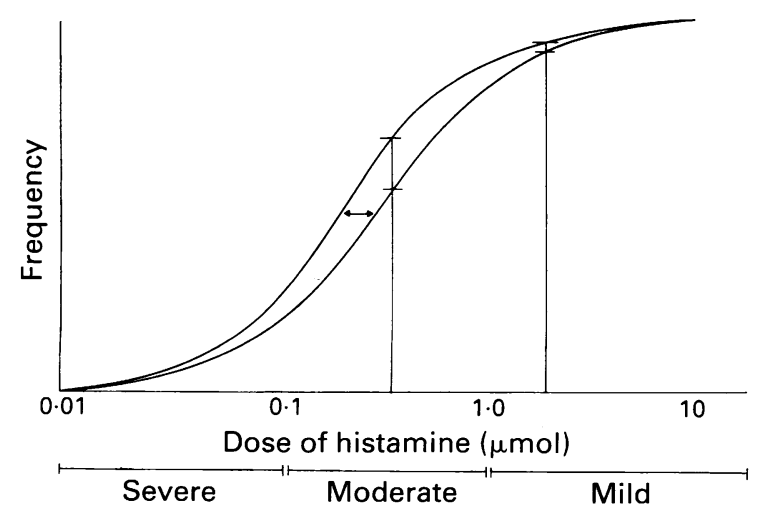

Figure 2 Theoretical frequency distribution of the severity of asthma as measured by the $P C_{20}$ to histamine. A small change in bronchial hyperresponsiveness $(\leftrightarrow)$ results in a large change in the proportion of patients with moderate asthma (adapted from Mitchell ${ }^{11}$ with permission of the author).
Subgroup analysis in our study population showed that the adverse effect on lung function was greatest in allergic and reversible asthmatic patients who were continuously treated with salbutamol. ${ }^{15}$ There was a significant doseresponse relationship between the mean daily dose of salbutamol and the decline in $\mathrm{FEV}_{1}$ during one year. The more salbutamol used per day by the patients, the more rapid their annual decline in $\mathrm{FEV}_{1}(65 \mathrm{ml}$ decline in $\mathrm{FEV}_{1}$ per mean daily dose of $400 \mu \mathrm{g}$ salbutamol, $p=0.02) .{ }^{16}$ As the treatment regimen was based on random allocation, patients taking the maximum dose of drugs did not differ in baseline characteristics from those taking lower dosages. The results were therefore not biased by differences in the severity of asthma at the start of the study.

A possible explanation for the larger decline in $\mathrm{FEV}_{1}$ in asthmatic patients who used salbutamol has been proposed by Dugas et al ${ }^{17}$ who have shown that $\beta_{2}$ adrenergic drugs have dose related stimulating effects on several inflammatory mediators specific to asthma. These mediators maintain the epithelial damage of the airways in asthma which makes the airway wall more sensitive to penetration of antigens. The increase in antigen load aggravates the inflammation which probably contributes to the rapid decline in $\mathrm{FEV}_{1}$ seen in allergic patients with asthma. ${ }^{18}$

It has been hypothesised that bronchoconstriction induced by exposure to allergens is a primitive defence mechanism that prevents irritants from entering the lower airways. ${ }^{19}$ Heparin would be released from mast cells to limit the acute inflammatory response to antigens, and this release would be inhibited by $\beta_{2}$ adrenergic drugs. Inhibition of this defence system by $\beta_{2}$ adrenergic drugs would thus lead to an increased irritant load and aggravated inflammation. ${ }^{19}$ As stabilising mast cells have never been shown to increase inflammation, this last hypothesis seems unlikely.

\section{Bronchodilators in combination with anti-inflammatory treatment}

Clinically it is probably more important to know what effect bronchodilators have on BHR when used in combination with anti-inflammatory drugs. It is generally accepted that if asthmatic patients need to inhale a bronchodilator more than once daily, it is advisable to add anti-inflammatory medication. ${ }^{20}$

In the study of Haahtela et al an inhaled steroid (budesonide $1200 \mu \mathrm{g}$ daily) combined with supplementary inhaled terbutaline improved BHR compared with the effect of a bronchodilator alone (terbutaline $750 \mu \mathrm{g}$ daily). ${ }^{8}$ The combination of a bronchodilator (terbutaline $2000 \mu \mathrm{g}$ daily) with an inhaled steroid (beclomethasone $800 \mu \mathrm{g}$ daily) has been shown to improve BHR by almost two doubling doses in $\mathbf{P C}_{20}$ histamine during the first year of study compared with bronchodilator alone. ${ }^{9} \mathrm{~A}$ comparable result was observed in an eight week study on asthmatic children with the same drugs. ${ }^{21}$ In another study a comparison of salbutamol plus theophylline $v$ salbutamol plus beclomethasone in asthmatic patients inadequately controlled with salbutamol alone showed a clear improvement in BHR within three weeks of inhaled steroid treatment, whereas no change occurred during theophylline treatment. ${ }^{22}$ Even in mild non-steroid dependent asthmatic patients a low dose of an inhaled steroid ( $400 \mu \mathrm{g}$ budesonide daily) improved BHR fourfold when given for one year, compared with bronchodilator alone. ${ }^{23}$ All these studies provide abundant evidence that the combination of a bronchodilator with an inhaled steroid clearly improves BHR, while a bronchodilator alone has no effect. 
A study by our group investigated whether rapid progression of patients with asthma or chronic obstructive airways disease (COPD) could be reversed or slowed by additional anti-inflammatory treatment. ${ }^{24}$ The study population comprised a subgroup of 56 of the 144 patients who completed the two year bronchodilator study. ${ }^{7}$ During the first two years these 56 patients ( 28 with asthma, 28 with COPD) had a rapid annual decline in $\mathrm{FEV}_{1}$ of $160 \mathrm{ml} /$ year with an average of two exacerbations per year. They were additionally treated with an inhaled steroid (beclomethasone $800 \mu \mathrm{g}$ daily) for a further two years. In the patients with asthma the $\mathrm{PC}_{20}$ decreased by 0.4 doubling dose/year during bronchodilator treatment, but increased to $1 \cdot 1$ doubling dose/year during steroid treatment. In the patients with COPD no improvement in $\mathrm{PC}_{20}$ was observed.

Other studies have appeared in which the effects of different anti-inflammatory drugs (steroid $v$ cromoglycate or nedocromil) were compared. ${ }^{25-27}$ In two ${ }^{25}{ }^{26}$ the combination of an inhaled steroid with a bronchodilator had a more favourable effect on BHR than the combination of cromoglycate (or nedocromil) with a bronchodilator, while in the third study it had a comparable effect. ${ }^{27}$ This difference in effect was probably the consequence of patient selection: the former two studies included (mainly) patients with allergic asthma while the latter study comprised patients with non-allergic asthma.

If the combination of a bronchodilator with a steroid is superior to the use of bronchodilators alone, there is still debate as to whether the additional bronchodilator should be used continuously or on demand. This question was addressed by Sears et al. ${ }^{28}$ In their study 50 of the 64 participating patients used inhaled corticosteroids and two others received cromoglycate (therefore only 12 patients received bronchodilator as single treatment). It was shown that $6 \%$ of the 64 asthmatic subjects had an increased BHR during six months of intermittent use of fenoterol, compared with $34 \%$ during continuous use of $800 \mu \mathrm{g}$ fenoterol daily $(\mathrm{p}=0 \cdot 0005)$. Although the study was carried out with fenoterol, Sears suggested that the adverse effect was probably not specific to fenoterol but to $\beta_{2}$ adrenergic drugs as a class. The result of this study might indicate that the bronchodilator should preferably be taken in low dosage or on demand when used in combination with a steroid. This study is, however, an isolated one and has to be confirmed by others.

\section{Long acting bronchodilators}

There is no convincing evidence that long acting $\beta_{2}$ adrenergic drugs (salmeterol and formoterol) have antiinflammatory properties, although they may have some non-bronchodilator properties which might be useful in the treatment of asthma. ${ }^{29} 30$ There is, however, no evidence that these additional properties contribute to the effect of these drugs in treating asthma. All trial data available so far carry no clear indication of action of the drugs other than bronchodilator properties. ${ }^{31}$

Studies have shown that there is no evidence that long term treatment with salmeterol ${ }^{32}$ or formoterol ${ }^{33}$ leads to tolerance of their bronchodilating effect. There is a suggestion, however, that salmeterol (100 $\mu \mathrm{g}$ daily for eight weeks as monotherapy) causes tolerance to its protective effect against methacholine, despite well maintained bronchodilation. ${ }^{34}$ This tolerance might be the consequence of a rebound deterioration, as BHR was measured 36 hours after interrupting regular treatment. No such rebound effect was observed after stopping salmeterol at the end of the study. ${ }^{34}$ If this observation is confirmed by physiological stimuli other than methacholine, it might indicate that in the long term the drug does not protect against provocative stimuli. As no tolerance to the bronchodilator ability of the drug was observed, patients will probably not notice this increase in susceptibility to acute bronchoconstriction.

We have recently expressed our concern that patients may be misled by the apparent wellbeing produced by the long acting bronchodilators, as they are more effective in suppressing symptoms-for example, morning breathlessness-and may therefore suppress the subjective need for anti-inflammatory treatment. ${ }^{35}$ This concern increased when we reanalysed our data of the two year intervention study with short acting bronchodilators ${ }^{7}$ and discovered that there was some correlation between the symptoms experienced and decline in lung function in symptomatically treated patients, but that there was no correlation at all in continuously treated patients. ${ }^{36} \mathrm{~A}$ plausible explanation for this finding may be that, because of the rapid bronchodilator response in the day to day control of symptoms, continuous bronchodilation masks the ongoing decline in lung function and any deterioration of the disease. Patients who receive continuous bronchodilator treatment may better tolerate potentially adverse situations and may, as a result, be more exposed to sensitising agents. ${ }^{37}$ If long acting bronchodilators are more effective at suppressing symptoms, they may suppress the subjective need for anti-inflammatory medication to an even greater extent. This has already been observed during long term use of formoterol. ${ }^{38}$ As long as it is uncertain which long term effects the long acting $\beta_{2}$ adrenergic drugs have on BHR, patients should be instructed to use these drugs carefully and only in combination with anti-inflammatory medication.

\section{Conclusion}

We conclude that monotherapy with bronchodilators does not, in general, increase BHR. In subgroups of patients and with high dosages of a $\beta_{2}$ adrenergic drug it may have such an effect, although it is small and of doubtful clinical relevance. There are indications that the decline in lung function increases during continuous use of a bronchodilator when compared with treatment on demand. This needs to be confirmed in studies of longer than two years before definite conclusions can be drawn about the effect of continuous bronchodilator treatment on the progression of the disease.

There is abundant evidence that the combination of a bronchodilator with an inhaled steroid improves BHR compared with the use of a bronchodilator alone. It is advised that the bronchodilator should be taken in a low dosage or on demand when used in combination with a steroid. More research is needed to decide which additional bronchodilator drugs should be used (and in what dose) when the patient is treated with anti-inflammatory drugs.

CP VAN SCHAYCK CLA VAN HERWAARDEN Department of General Practice and Department of Lung Diseases, Nijmegen University, PO Box 9101 6500 HB Nijmegen,

Correspondence to: Dr van Schayck

1 Kraan J, Koëter GH, Mark Th W van der, Sluiter HJ, Vries $\mathrm{K}$ de. Changes in bronchial hyperreactivity induced by 4 weeks of treatmen with antiasthmatic drugs in patients with allergic asthma: a comparison between budesonide and terbutaline. F Allergy Clin Immunol 1985; 76:628-36.

2 Vathenen AS, Knox AJ, Higgins BG, Britton JR, Tattersfield AE Rebound increase in bronchial responsiveness after treatment with inhaled terbutaline. Lancet 1988;i:554-8. 
3 Kerrebijn KF, Essen-Zandvliet EEM, Neijens HJ. Effect of long-term treatment with inhaled corticosteroids and beta-agonists on the bronchial responsiveness in children with asthma. $f$ Allergy Clin Immunol 1987;79:653-9.

4 Raes M, Mulder P, Kerrebijn KF. Long-term effect of ipratropium bromide and fenoterol on the bronchial hyperresponsiveness to histamine in children with asthma. $\mathcal{F}$ Allergy Clin Immunol 1989;84:874-9.

5 Schayck CP van, Graafsma SJ, Visch MB, Dompeling E, Weel C van, Herwaarden CLA van. Increased bronchial hyperresponsiveness after inhaling salbutamol during one year is not caused by subsensitization to salbutamol. F Allergy Clin Immunol 1990;86:793-800.

6 Schuster A, Kozlik R, Reinhardt D. Influence of short- and long-term inhalation of salbutamol on lung function and $\beta_{2}$-adrenoceptors of mononuclear blood cells in asthmatic children. Eur $\mathcal{f}$ Pediatr 1991; 150:209-13.

7 Schayck CP van, Dompeling E, Herwaarden CLA van, Folgering $\mathrm{H}_{\text {, }}$ Verbeek ALM, Hoogen HJM van den, et al. Bronchodilator treatment in moderate asthma and chronic bronchitis: continuous or on demand? A randomised controlled study. $B M \mathcal{Y}$ 1991;303:1426-31.

8 Haahtela T, Järvinen M, Kava T, Kiviranta K, Koshinen S, Lehtonen K, et al. Comparison of a $\beta_{2}$-agonist, terbutaline, with an inhaled corticosteroid, budesonide, in newly detected asthma. $N$ Engl $\mathcal{f}$ Med 1991; 325:388-92.

9 Kerstiens HAM, Brand PLP, Hughes MD, Robinson NJ, Postma DS, Sluiter HJ, et al. A comparison of bronchodilator therapy with or without inhaled corticosteroid therapy for obstructive airway disease. $N$ Engl ₹ Med 1992;327:1413-9.

10 Cockcroft DW, Killian DN, Mellon JA, Hargreave FE. Bronchial reactivity to inhaled histamine: a method and clinical survey. Clin Allergy 1977;7:235-9.

11 Mitchell EA. Is current treatment increasing asthma mortality and morbidity? Thorax $1989 ; 44: 81-4$

12 Crane J, Pearce N, Flatt A, Burgess C, Jackson R, Kwong T, et al. Prescribed fenoterol and death from asthma in New Zealand, 1981-83. case-control study. Lancet 1989;i:917-22.

13 Spitzer WO, Suissa S, Ernst P, Horwitz RI, Habbick B, Cockcroft D, et al. The use of $\beta$-agonists and the risk of death and near death from asthma. N Engl f Med 1992;326:501-6.

14 Burrows B, Lebowitz MD. The $\beta$-agonist dilemma. $N$ Engl f Med 1992; 326:560-1.

15 Dompeling E, Schayck CP van, Broek PJJA van den, Weel $C$ van. The decline in lung function during continuous versus on demand use of salbutamol and ipratropium brom
Respir Dis 1992;145(suppl 2);A61.

16 Schayck CP van, Kraak A, Dompeling E, Folgering H, Weel C van Dose-response relationship between the decline in lung function and the daily dose of salbutamol and ipratropium bromide. Am Rev Respir Dis 1992;145(suppl 2);A61.

17 Dugas B, Lagente V, Mencia-Huerta JM, Braquet P. Pharmacological modulation of the expression of the low affinity IgE receptor. In Gordon J, ed $A$ novel multifunctional regulator of the immune system that binds IgE. Basel: Karger, 1991, vol 29, 76-93.

18 Schayck CP van, Dompeling E, Herwaarden CLA van, Wever AMJ, Weel $C$ van. Interacting effects of atopy and bronchial hyperresponsiveness on the annual decline in lung function and the exacerbation rate in asthon the annual decline in lung function and the

19 Page CP. One explanation of the asthma paradox: inhibition of natura anti-inflammatory mechanism by $\beta_{2}$-agonists. Lancet 1991;337:717-20.

20 British Thoracic Society. Guidelines for the management of asthma in adults: I. Chronic persistent asthma. BMF 1990;301:651-3.
21 Waalkens HJ, Gerritsen J, Koëter GH, Krouwers FH, Aalderen WM, Knol $\mathrm{K}$. Budesonide and terbutaline or terbutaline alone in children with mild asthma: effects on bronchial hyperresponsiveness and diurnal variation in peak flow. Thorax 1991;46:499-503.

22 Dutoit II, Salome CM, Woolcock AJ. Inhaled corticosteroids reduce the severity of bronchial hyperresponsiveness in asthma but oral theophyline does not. Am Rev Respir Dis 1987;136:1174-8.

23 Juniper EF, Kline PA, Vanzieleghem MA, Ramsdale EH, O'Byrne PM Hargreave FE. Effect of long-term treatment with inhaled corticosteroid (budesonide) on airway hyperresponsiveness and clinical asthma in nonsteroid-dependent asthmatics. Am Rev Respir Dis 1990;142:832-6.

24 Dompeling E, Schayck CP van, Grunsven PM van, Herwaarden CLA van, Akkermans R, Molema J. Showing the deterioration of asthma and COPD observed during bronchodilator therapy by adding inhaled corticosteroids: a four year prospective study. Ann Intern Med 1993;118:770-8.

25 Molema J, Herwaarden CLA van, Folgering $H$. Effects of long-term treatment with inhaled cromoglycate and budesonide on bronchial hyperresponsiveness in patients with allergic asthma. Eur Respir $f$ 1989; 2:308-16.

26 Svendsen UG, Frolund L, Madsen F, Nielsen NH. A comparison of the effects of nedocromil sodium and beclomethasone dipropionate on pulmonary function, symptoms and bronchial responsiveness in patients with asthma. F Allergy Clin Immunol 1989;84:224-31.

27 Bel EH, Timmers MC, Hermans J, Dijkman JH, Sterk PJ. The long-term effects of nedocromil sodium and beclomethasone dipropionate on bronchial responsiveness to methacholine in nonatopic asthmatic subjects. Am Rev Respir Dis 1990;141:21-8.

28 Sears MR, Taylor DR, Print CG, Lake DC, Li O, Flannery EM, et al. Regular inhaled beta-agonist treatment in bronchial asthma. Lancet 1990;336:1391-6.

29 Twentyman OP, Finnerty JP, Harris A, Palmer J, Holgate ST. Protection against allergen-induced asthma by salmeterol. Lancet 1990;336: 1338-42.

30 Dahl $R$, Pederson B, Venge $P$. The influence of inhaled salmeterol on bronchial inflammation. A bronchoalveolar lavage study in patients with bronchial asthma. Am Rev Respir Dis 1991;143:A649.

31 Clark TJH. Asthma management: the future role of salmeterol. Eur Respir $\mathcal{F}$ 1991;1:304-8.

32 Ullman A, Hedner J, Svedmyr N. Inhaled salmeterol and salbutamol in asthmatic patients, an evaluation of asthma symptoms and the possible
development of tachyphylaxis. Am Rev Respir Dis 1990;142:571-5.

33 Arvidsson P, Larsson S, Lofdahl CG, Melander B, Wahlander L, Svedmyr N. Formoterol, a new long-acting bronchodilator. Eur Respir $\mathcal{f}$ 1989;2:325-30.

34 Cheung D, Timmers MC, Aeilko H, Bell EH, Dÿkman JP, Sterk PJ Long-term effects of a long-acting $\beta_{2}$-adrenoceptor agonist, salmeterol on airway hyperresponsiveness in patients with mild asthma. $N$ Engl $\mathcal{f}$ Med 1992;327:1198-203.

35 Schayck CP van, Dompeling E, Weel C van, Akkermans RP. Bronchodilator treatment in asthma: continuous or on demand? $B M F$ 1992;304:503-4.

36 Schayck CP van, Folgering $H$, Otter J den, Tirimanna $P$, Weel $C$ van. Is the continuous use of bronchodilators masking the progression of the continuous use of bronchodilators masking the p

37 Barnes PJ. Effect of corticosteroids on airway hyperresponsiveness. $\mathrm{Am}$ Rev Respir Dis 1990;141:S70-6.

38 Arvidsson P, Larsson S, Lofdahl CG, Melander B, Svedmyr N, Wahlander $L$. Inhaled formoterol during one year in asthma: a comparison with salbutamol. Eur Respir $f$ 1991;4:1168-73. 